\title{
Morfoanatomia de Memora nodosa (Silva Manso) Miers, Bignoniaceae
}

\author{
Leonice M. F. Tresvenzol, ${ }^{1}$ Tatiana S. Fiuza, ${ }^{1}$ Maria Helena Rezende, ${ }^{2}$ Heleno D. Ferreira, ${ }^{2}$ \\ Maria Teresa F. Bara, ${ }^{1}$ Daniel T. Zatta, ${ }^{1}$ José R. Paula ${ }^{*}$,
}

\author{
${ }^{1}$ Laboratório de Pesquisa em Produtos Naturais, Faculdade de Farmácia, Universidade Federal de Goiás, \\ Caixa Postal 131, 74001-970 Goiânia-GO, Brasil, \\ ${ }^{2}$ Laboratório de Anatomia Vegetal, Instituto de Ciências Biológicas, Universidade Federal de Goiás, \\ Caixa Postal 131, 74001-970 Goiânia-GO, Brasil.
}

\begin{abstract}
RESUMO: Memora nodosa (Silva Manso) Miers, Bignoniaceae, é uma planta do Cerrado utilizada popularmente como cicatrizante de úlceras e feridas externas (folhas e caules). O objetivo deste trabalho foi caracterizar morfologicamente essa espécie e fazer o estudo anatômico de suas folhas. O estudo morfológico foi realizado à vista desarmada e com o auxílio de microscópio estereoscópico. Para o estudo anatômico as folhas foram seccionadas e as lâminas histológicas confeccionadas de acordo com as técnicas convencionais. Memora nodosa é um arbusto com folhas opostas cruzadas, recompostas, bipinadas, imparipinadas, com foliólulos pequenos, lanceolados, verde-escuros e brilhantes. A inflorescência é racemosa com flores infundibuliformes e corola amarelo-ouro; glândulas nectaríferas são observadas no terço superior do cálice; androceu com quatro estames férteis, didínamos e um estaminódio reduzido; gineceu com estilete terminal, ovário súpero, assentado sobre um disco nectarífero. O fruto é do tipo cápsula septífraga achatada, com sementes aladas. Anatomicamente a lâmina do foliólulo é hipoestomática com estômatos predominantemente paracíticos. O parênquima paliçádico é pluriestratificado, ocupando cerca de dois terços do mesofilo dorsiventral. Tricomas glandulares e tectores são observados, em maior número, nas folhas jovens.
\end{abstract}

Unitermos: Plantas medicinais, Cerrado, Bignoniaceae, morfoanatomia.

\begin{abstract}
Morpho-anatomy of Memora nodosa (Silva Manso) Miers, Bignoniaceae." Memora nodosa (Silva Manso) Miers, Bignoniaceae, is a Brazilian Savannah plant, popularly used as external wound and ulcer healing (leaves and stems). The goal of this research was to perform the morphological study of $M$. nodosa species and the anatomical study of its leaves. The morphological study was done to the naked eye and with the aid of a stereoscopic microscope. For the anatomical study leaves were sectioned and histological slides made in accordance with conventional techniques. Memora nodosa is a shrub with decussate leaves recomposed, bipinnate, imparipinnate with small leaflets, lanceolate, dark green and shining. The inflorescence is racemose with infundibuliform flowers and gold yellow corolla; nectar glands are observed in the upper third calyx; androecium with four fertile stamens, didynamus and one staminode; gynoecium with terminal style, superior ovary, seated on a nectary disc. The fruit is flattened septifragal capsule with winged seeds. Anatomically, the blade leaflet is hypostomatic with predominantly paracytic stomata. The palisade parenchyma is pluriseriate, occupying about two thirds of the dorsiventral mesophyll. Glandular and non-glandular trichomes are observed in greater numbers in the young leaves.
\end{abstract}

Keywords: Medicinal plants, Brazilian Savannah, Bignoniaceae, morpho-anatomy.

\section{IINTRODUÇÃO}

Memora, gênero de Bignoniaceae, pertencente à tribo Bignonieae, apresenta 72 espécies, até o momento pouco estudadas. A morfologia de algumas espécies de Memora foi realizada por Gentry (1974, 1977, 1978), enquanto as características gerais das folhas e a anatomia da epiderme desse gênero foram relatadas por Vidal (1978). Mais recentemente, Rodrigues et al. (2002) realizaram o estudo morfoanatômico de Memora 
allamandiflora Bureau ex K. Schum. Estudo etnobotânico realizado por Gentry (1992) mostrou que na região do rio Xingu e no Peru Memora allamandiflora e Memora cladotricha Sandwith, respectivamente, eram utilizadas na pesca, como veneno ou "vinho" para peixes e Memora flavida (DC.) Bureau \& K. Schum. era empregada no tratamento de dores ósseas e musculares por tribos do Suriname.

Em Goiás, Minas Gerais e Mato Grosso encontrase Memora nodosa (Silva Manso) Miers (Vidal, 1978; Mobot, 2008), conhecida popularmente como carobinha (Silva, 1998), carobinha-do-campo, caroba-amarela (Siqueira, 1988) e bambuzinho. O infuso das folhas e dos caules dessa planta é empregado popularmente no tratamento de úlceras e feridas externas (Siqueira, 1988), enquanto o chá de suas raízes é utilizado internamente para dores abdominais e externamente no combate à sarna (Silva, 1998).

A descrição morfológica das partes aéreas de $M$. nodosa, encontrada na literatura, foi realizada por Bureau \& Schumann (1897). A prospecção fitoquímica realizada por Tresvenzol et al. (2005) evidenciou a presença de glicosídeos saponínicos e flavonoides nas folhas, nos caules e nas raízes e de óleo essencial nas folhas. $\mathrm{Na}$ análise do óleo essencial das folhas, benzaldeído $(91,5 \%)$ e 1-octen-3-ol (6\%) foram os componentes majoritários (Tresvenzol et al., 2009).

Soares (2008) verificou que o extrato etanólico das folhas de $M$. nodosa apresentou atividade moderada contra ninfas do carrapato Amblyomma cajannense, enquanto Tresvenzol et al. (2009) relataram atividade in vitro contra bactérias Gram-positivas e contra o fungo Candida albicans nas frações hexano e diclorometano, obtidas das raízes.

Assim, o presente trabalho teve como objetivo contribuir com o estudo morfológico de M. nodosa e caracterizar anatomicamente suas folhas, visando fornecer subsídios para a identificação botânica dessa planta medicinal.

\section{MATERIAL E MÉTODOS}

\section{Material botânico}

Para o estudo morfoanatômico foram utilizados exemplares de Memora nodosa (Silva Manso) Miers, Bignoniaceae, coletados em regiões de Cerrado, nos municípios de Senador Canedo-GO, Brasil (16o45'01's, 49o07'50,6"W, altitude de $717 \mathrm{~m}$ ) e de Nerópolis-GO, Brasil (16 $25^{\prime} 15,6^{\prime \prime} \mathrm{S}, 49^{\circ} 10^{\prime} 07,8^{\prime \prime}$, altitude de 818 m). O material botânico foi identificado pelo Professor Doutor Heleno Dias Ferreira e as exsicatas depositadas no Herbário da Universidade Federal de Goiás sob os registros UFG/29981 (Senador Canedo) e UFG/29982 (Nerópolis).

\section{Caracterização morfológica}

A caracterização macroscópica foi realizada à vista desarmada e com o auxílio de microscópio estereoscópico, seguindo os parâmetros de Gonçalves \& Lorenzi (2007); Judd et al. (1999); Vidal \& Vidal (2000). As imagens das estruturas estudadas foram registradas por câmera digital Sony (MPEG).

\section{Caracterização anatômica}

O estudo anatômico das folhas foi realizado utilizando microscopia de luz. A lâmina dos foliólulos também foi analisada por microscopia eletrônica de varredura (MEV).

\section{Microscopia de luz}

Foram coletadas folhas completamente expandidas, provenientes do quinto nó, folhas jovens, do primeiro e segundo nós, e gavinhas. Dessas folhas foram retirados fragmentos da região mediana e do bordo da lâmina do foliólulo, da região mediana da raque, da ráquila (raque de segunda ordem), do pecíolo, do peciólulo e da gavinha.

As secções à mão livre foram realizadas em material fresco. As lâminas histológicas foram confeccionadas utilizando secções paradérmicas e transversais da lâmina do foliólulo; secções transversais do pecíolo, do peciólulo, da raque, da ráquila e da gavinha. Os cortes foram submetidos à dupla coloração com azul de Alcian/safranina (Kraus \& Arduin, 1997) ou azul de astra/fucsina básica (Luque et al., 1996) e montados em glicerina a $50 \%$.

A dissociação da epiderme foi realizada segundo Ghouse \& Yunus (1972) e as amostras submetidas à coloração com azul de metileno a $1 \%$ ou safranina a $1 \%$. Para os testes microquímicos, as secções foram coradas com cloreto férrico a $1 \%$ e reagente de Sudan IV (Costa, 2001).

As fotomicrografias foram realizadas em fotomicroscópio ZEISS Axioskop, utilizando-se filme Kodacolor ASA 100.

\section{Microscopia Eletrônica de Varredura}

Amostras da porção mediana da lâmina do foliólulo foram fixadas em solução de Karnovsky modificada, por $24 \mathrm{~h}$. Posteriormente, essas amostras foram transferidas para um tampão de cacodilato de sódio e tetróxido de ósmio (1:1) por $1 \mathrm{~h}$, lavadas em água destilada, desidratadas em série etanólica crescente $(30$, 50,70 e $90 \% \mathrm{v} / \mathrm{v}$ ) durante $15 \mathrm{~min}$ e em etanol absoluto durante 10 min (Bozzola \& Russel, 1992). Em seguida, os fragmentos foram levados à secagem pelo ponto crítico de $\mathrm{CO}_{2}$, no aparelho de secagem ao Ponto Crítico 
da Balzers CPD30, fixados com fita adesiva de dupla face em pequenos suportes e metalizados em ouro, com camada de cobertura de aproximadamente $40 \mathrm{~nm}$ por 2 min, em aparelho metalizador Zeiss DSM-962.

A análise foi realizada em microscópio de varredura JEOL-JSM 840A e as eletromicrografias obtidas em filme FUJI NEOPAN Asa 100.

\section{RESULTADOS}

A espécie é encontrada no Bioma Cerrado de Goiás de forma esparsa, quando a vegetação nativa se encontra preservada. Em áreas abertas e ensolaradas, a planta propaga-se rapidamente e é facilmente visualizada às margens de rodovias, em terrenos baldios e em áreas desmatadas para práticas agropecuárias. Um rebrotamento rápido e vigoroso, muitas vezes seguido de floração é observado quando a planta é submetida à poda (parcial ou total) e à ação do fogo.

A planta, em seu habitat natural, geralmente floresce de março a agosto, mas exemplares floridos podem ser encontrados à margem de rodovias e em terrenos baldios praticamente durante todo o ano.

\section{Caracterização morfológica}

Essa planta é um arbusto perene, com 150 a $300 \mathrm{~cm}$ de altura, cujos caules se agrupam formando touceiras (Figura 1A). O caule é cilíndrico com cor variando do verde ao marrom-esverdeado, flexível, glabro e ceroso, piloso, quando jovem, com lenticelas organizadas longitudinalmente para a base. Os caules jovens são eretos, não ramificados, podendo se reunir formando touceiras, o que provavelmente justifica a denominação de bambuzinho dada a essa planta. Com menor freqüência, esses caules podem se fixar através de gavinhas evidenciando característica trepadora. Com o desenvolvimento da planta, os caules se curvam e, após a floração, vários ramos surgem das axilas das inflorescências.

A raiz é pivotante, profunda, podendo atingir mais de $150 \mathrm{~cm}$ de comprimento e cerca de $15 \mathrm{~cm}$ de diâmetro. Na parte superior da raiz encontra-se uma estrutura dilatada, arredondada ou alongada, de onde se originam os caules.

As folhas têm filotaxia oposta cruzada, raramente verticilada, sendo recompostas, bipinadas com dois ou três pares de folíolos, mais raramente quatro ou cinco pares. Os folíolos possuem geralmente cinco a sete foliólulos, contudo exemplares com nove a onze foliólulos também são encontrados. As folhas completamente expandidas possuem 32 a $57 \mathrm{~cm}$ de comprimento e 33 a $75 \mathrm{~cm}$ de largura. Os folíolos são opostos, cartáceos, glabros, verde-escuros na face adaxial e verde-claros na face abaxial, muito brilhantes nas folhas jovens, lanceolados ou ovalado-lanceolados, de base assimétrica, subarredondada ou cuneada, ápice agudo, margens inteiras. Os foliólulos são peninérveos, com padrão de venação camptódromo-broquidódromo. Os foliólulos apresentam 2,0 a 8,5 cm de comprimento por 0,2 a 1,2 cm de largura. Variação foliar é frequente nessa espécie. As folhas do terço superior dos ramos jovens e das axilas das inflorescências geralmente apresentam apenas dois folíolos e uma gavinha terminal. A raque é subcilíndrica, sulcada superiormente, glabra, com 8 a $30 \mathrm{~cm}$ de comprimento. A ráquila também é subcilíndrica, sulcada superiormente, glabra, com 3 a 17 $\mathrm{cm}$ de comprimento. As raques e as ráquilas apresentam nodosidades na face abaxial, no ponto de inserção dos folíolos e dos foliólulos. O pecíolo é subcilíndrico, reto ou sulcado na face superior, alargado na base, glabro, medindo de 2,0 a 12,5 $\mathrm{cm}$ de comprimento (Figura 1B).

A inflorescência é racemosa, terminal ou axilar, às vezes moderadamente ramificada formando panículas, contendo 10 a 16 flores monoclinas. As flores possuem pedicelos curtos de cor verde-claro, glabros, com brácteas caducas. O cálice é tubulosoturbinado, de cor verde-claro, com 0,9 a $1,3 \mathrm{~cm}$ de comprimento, pentadentado (dentes com $0,1 \mathrm{~cm}$ ), glabro ou com tricomas minúsculos nos bordos; glândulas nectaríferas pequenas e proeminentes são observadas sobre as nervuras, no terço superior do cálice (Figura 1C). A corola é infundibuliforme com 6,3 a 7,3 cm de comprimento, cor amarelo-ouro, com tonalidade mais escura nos lobos, externamente glabra e internamente com tricomas na base dos estames. O gineceu apresenta estilete com 3,0 a 4,0 cm de comprimento, estigmas bilamelados, ovário súpero, com 0,3 a 0,4 $\mathrm{cm}$, bicarpelar, bilocular com até 12 óvulos. Presença de disco nectarífero na base do ovário. Androceu com quatro estames férteis, epipétalos, didínamos e um pequeno estaminódio $(0,4$ a $0,5 \mathrm{~cm})$, anteras amarelas com tecas de $0,3 \mathrm{~cm}$ de comprimento. As flores são muito visitadas por insetos, principalmente pelas formigas.

O fruto é do tipo cápsula septífraga com 8 a $33 \mathrm{~cm}$ de comprimento e 1,1 a $3,0 \mathrm{~cm}$ de largura, linear ou ligeiramente ondulado, achatado, fortemente comprimido, agudo nas duas extremidades, margens subonduladas e espessadas. O fruto seco é escuro externamente e, quando se abre, mostra duas valvas e uma coluna seminífera presa pela base e circundada por dois filamentos; as sementes, em número de 2 a 12 por fruto, são aladas e estão aderidas à coluna seminífera pelo hilo e pelas alas (Figura 1D).

\section{Caracterização anatômica}

\section{Lâmina do foliólulo}

Em vista frontal, as células epidérmicas do 


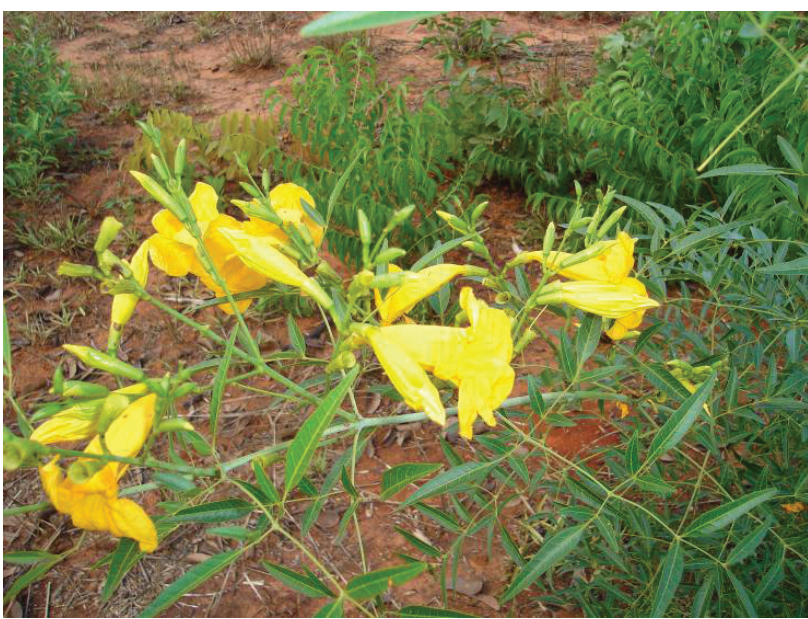

A

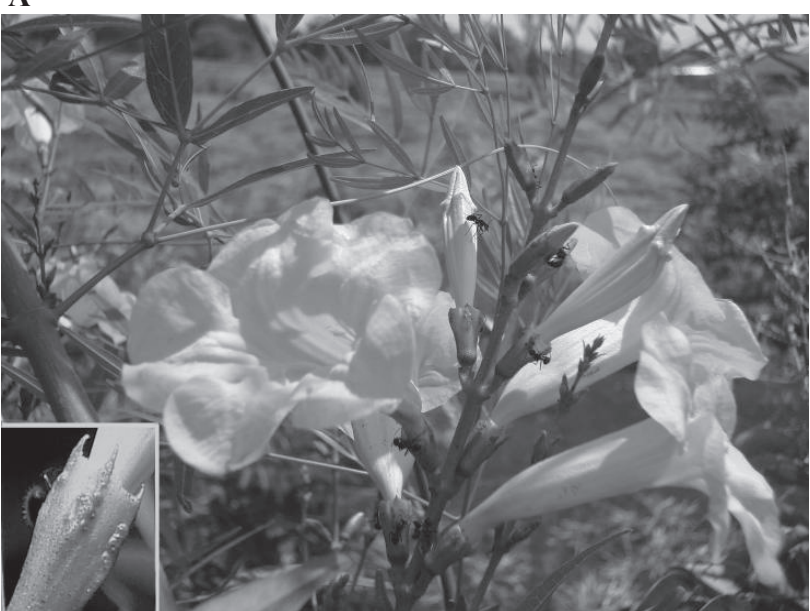

C

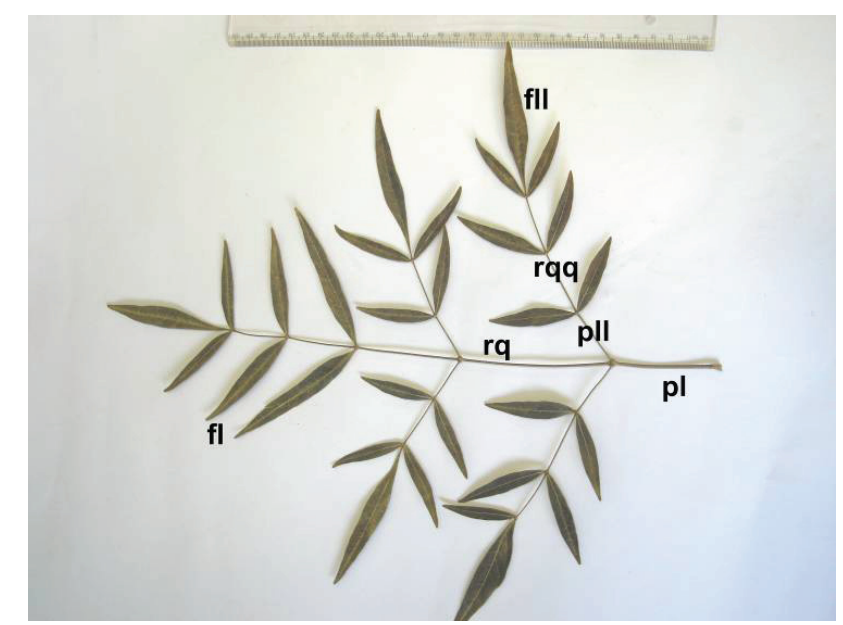

B

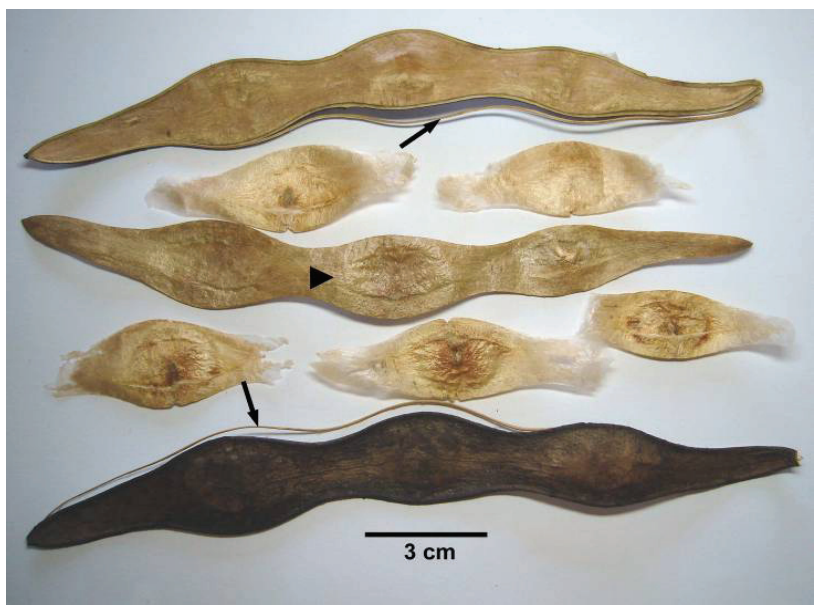

D

Figura 1. Morfologia de Memora nodosa (Silva Manso) Miers, Bignoniaceae. A. Aspecto geral da planta adulta. B. Aspecto geral da folha. C. Aspecto geral da inflorescência e detalhe do cálice evidenciando glândulas no terço superior. D. Aspecto geral dos frutos (seta) e sementes (ponta de seta). fl: folíolo; fll: foliólulo; rq: raque; rqq: ráquila; pl: pecíolo; pll: peciólulo.

foliólulo são poligonais com paredes retas ou levemente ondeadas nas faces adaxial (Figura 2A) e abaxial (Figura 2B). A epiderme é uniestratificada, sendo as células da face adaxial mais volumosas e revestidas por cutícula mais espessa que as da face abaxial. Os foliólulos são hipoestomáticos, com estômatos predominantemente paracíticos (Figura 2B), mais raramente anisocíticos e ciclocíticos. Observam-se na face abaxial, estômatos (Figuras 2C e 2D) e cicatrizes de tricomas circundados radialmente por células da epiderme, com aspecto de uma roseta.

A lâmina foliar é dorsiventral. O parênquima paliçádico, com até seis camadas de células, ocupa dois terços do mesofilo; o parênquima lacunoso é pluriestratificado com células de formatos variados. Os feixes vasculares menores estão envoltos por bainha parenquimática e esclerenquimática (Figura 3A). Alguns apresentam extensão de bainha em direção à face adaxial. Compostos fenólicos foram observados nos parênquimas paliçádico e lacunoso.

A região da nervura principal, em secção transversal, é convexa nas duas faces. A epiderme da face adaxial está revestida com cutícula espessa, com flange cuticular; subjacente à epiderme, observa-se o colênquima angular com três ou quatro camadas de células. O sistema vascular está disposto em formato circular, totalmente envolvido por tecido esclerenquimático (Figura 3B).

No bordo do foliólulo, a epiderme encontrase revestida por cutícula espessa e não se observam parênquimas paliçádico e lacunoso. Subjacente à epiderme, observa-se colênquima com duas a quatro camadas de células (Figura 3C).

\section{Raque e ráquila}

A raque (Figura 4A) e a ráquila (Figura 4B) apresentam face adaxial côncava e abaxial convexa, com duas pequenas projeções laterais. Anatomicamente, a raque e a ráquila apresentam organização estrutural semelhante, constituída porepidermeunisseriada revestida por cutícula espessa com flange cuticular; colênquima e parênquima na região cortical, com algumas células 


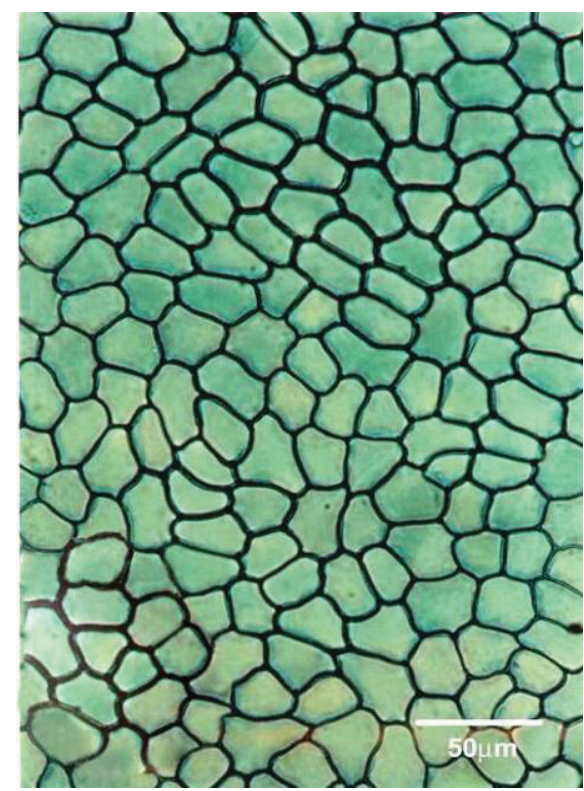

A

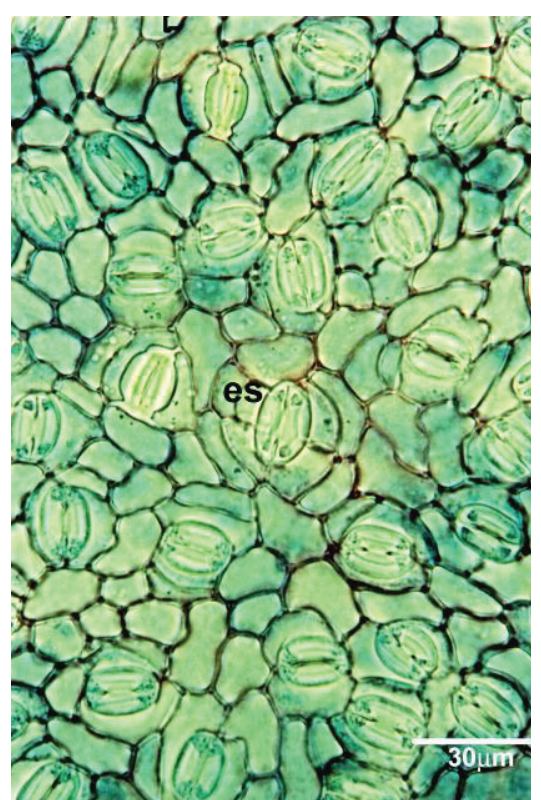

B

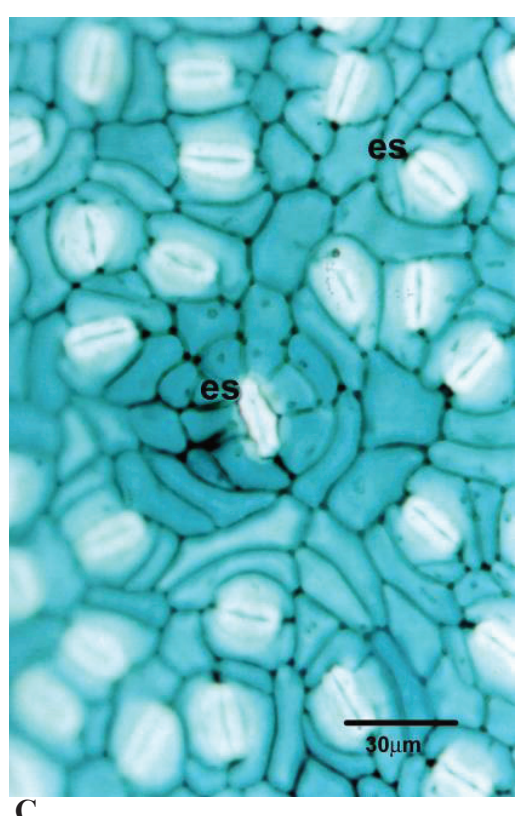

C

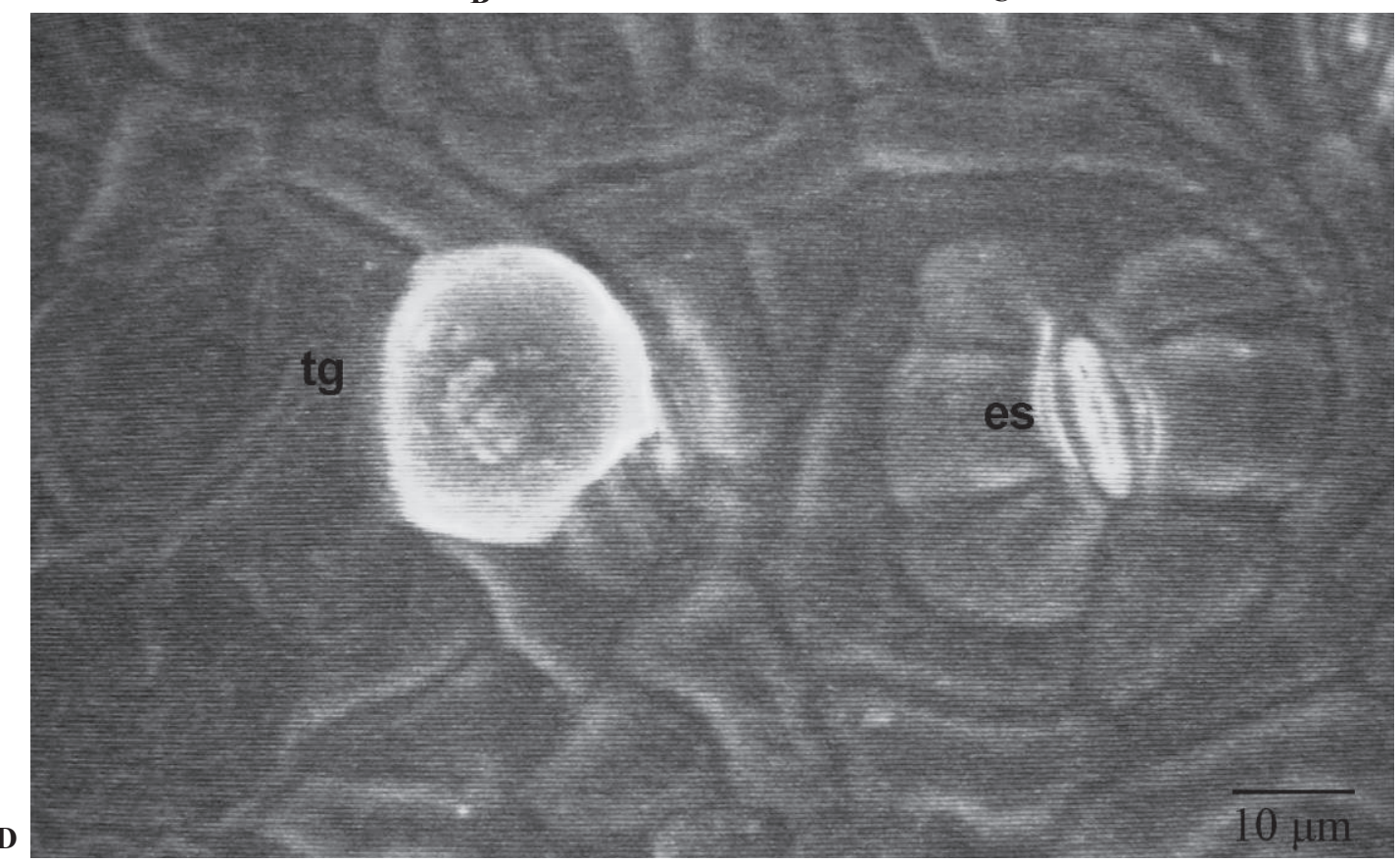

Figura 2. Epiderme do foliólulo da planta adulta de Memora nodosa (Silva Manso) Miers, Bignoniaceae. A. Vista frontal da face adaxial da epiderme. B. Vista frontal da face abaxial da epiderme evidenciando estômatos. C. Destaque de um estômato circundado radialmente por células da epiderme, com aspecto de uma roseta (centro) na face abaxial da epiderme. D. Detalhe do estômato em microscopia eletrônica de varredura. es: estômato; tg: pêlo glandular.

colenquimáticas parcialmente lignificadas (Figura 4C); sistema vascular envolto por bainha esclerenquimática e região central preenchida por parênquima medular, constituído por células de tamanhos variados (Figuras 4A a 4C).

\section{Peciólulo e Pecíolo}

O peciólulo é côncavo na face adaxial com duas projeções laterais e convexo na face abaxial (Figura 5A). O pecíolo apresenta face adaxial plana ou côncava e face abaxial convexa (Figura 5B). A organização estrutural do peciólulo e do pecíolo é semelhante e está constituída por epiderme unisseriada revestida por cutícula espessa com flange cuticular; parênquima cortical constituído por quatro a oito camadas de células; no pecíolo algumas células do parênquima cortical encontram-se parcialmente ou completamente lignificadas (Figura 5C); 
sistema vascular envolto por calotas esclerenquimáticas; na região central, o parênquima medular apresenta células de tamanhos variados, algumas com paredes espessas evidenciando pontoações (Figura 5D).

Tricomas tectores simples, com até três células são observados, em pequeno número, na face adaxial das raques, das ráquilas, dos pecíolos e dos peciólulos (Figura 6A). Tricomas glandulares capitados com pedicelo curto, cabeça pluricelular, globosa (Figura 6B) ou alongada (Figura 6C) e tricomas glandulares peltados (Figura 6D) são visualizados na lâmina foliar e demais estruturas das folhas jovens, raramente nas folhas completamente expandidas.

A

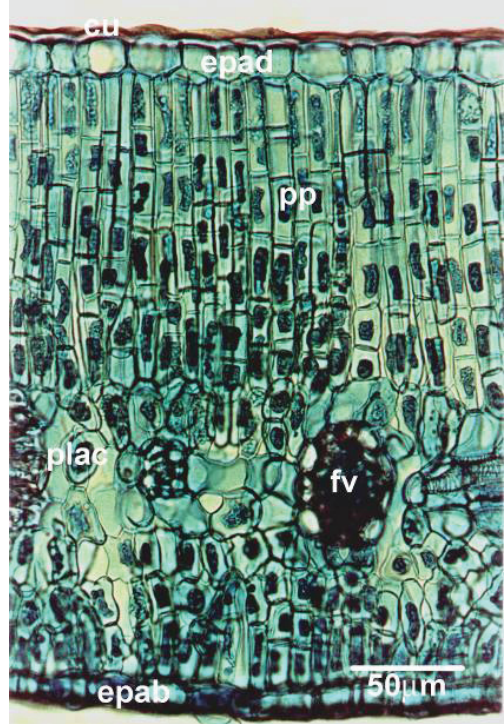

\section{Gavinhas}

A gavinha, em seção transversal, apresenta forma cilíndrica. A epiderme é unisseriada com cutícula espessa evidenciando flange cuticular; na região cortical observam-se colênquima angular e parênquima. O cilindro vascular é formado por feixes vasculares colaterais, com calotas esclerenquimáticas dispostas externamente ao floema. A região central está preenchida por parênquima medular, com células de tamanhos variados apresentando campos de pontoação primário.
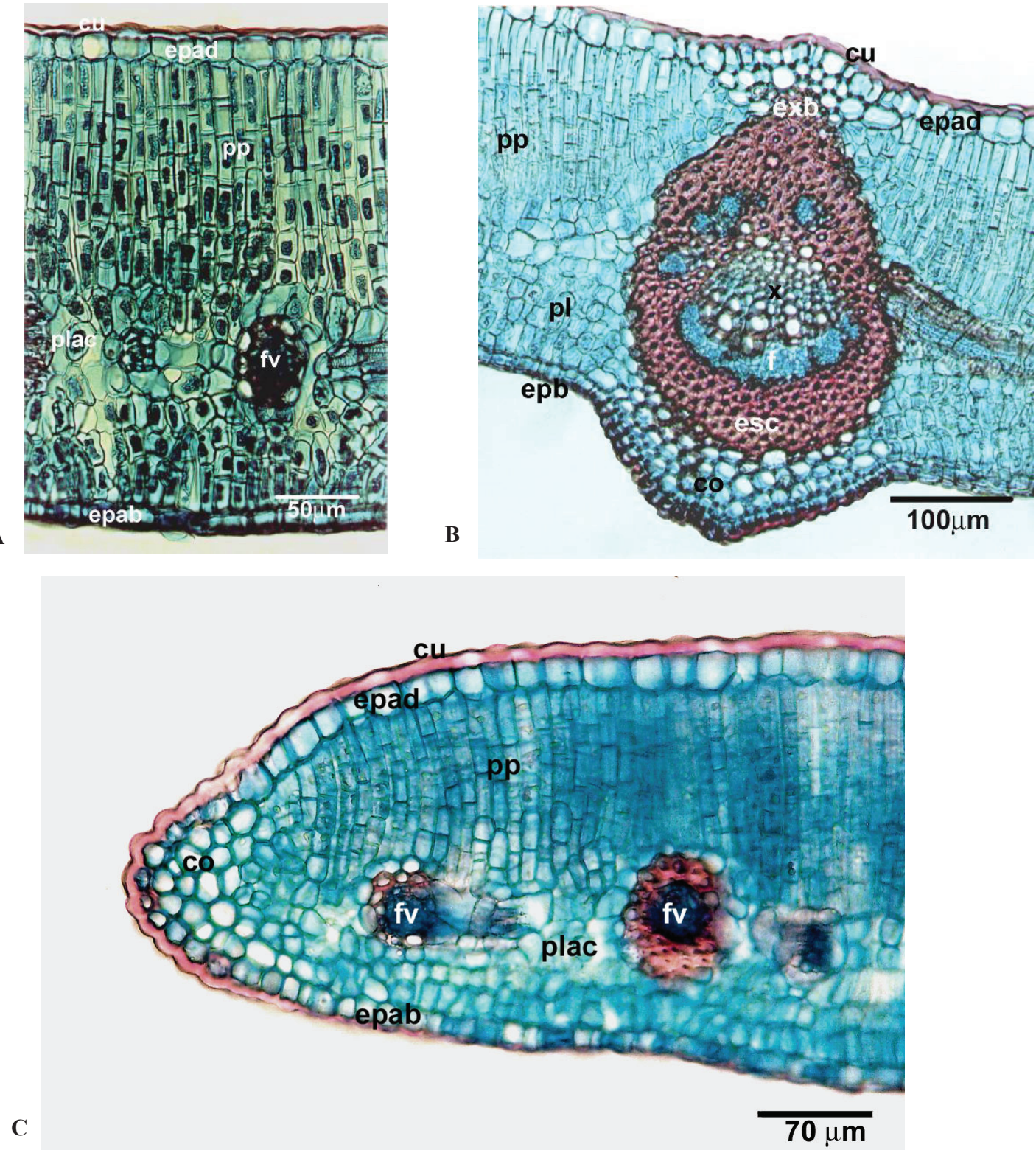

Figura 3. Detalhes da lâmina foliar, da nervura principal e do bordo do foliólulo de Memora nodosa (Silva Manso) Miers, Bignoniaceae, em secção transversal. A. Detalhe da epiderme, da cutícula, dos parênquimas paliçádico e lacunoso e de feixes vasculares de pequeno calibre. B. Aspecto geral da nervura principal. C. Aspecto geral do bordo do foliólulo. co: colênquima; cu: cutícula; epab: face abaxial da epiderme; epad: face adaxial da epiderme; esc: esclerênquima; exb: extensão da bainha; f: floema; fv: feixe vascular; plac: parênquima lacunoso; pp: parênquima paliçádico; x: xilema. 
A

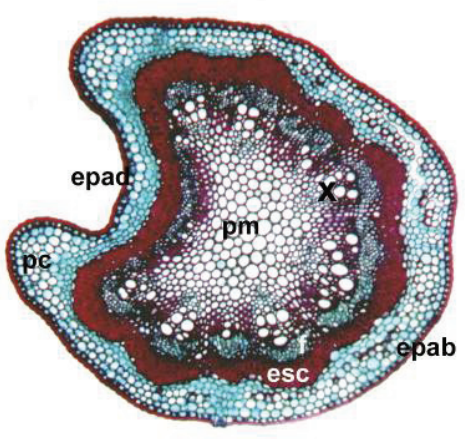

$\overline{200 \mu m}$

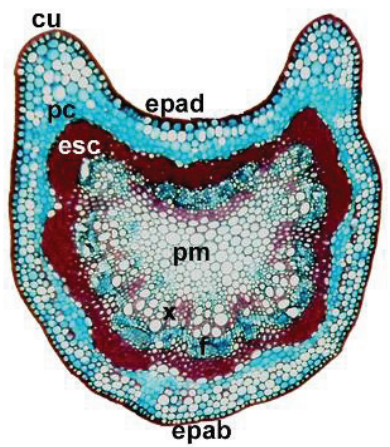

$\overline{200 \mu \mathrm{m}}$
C

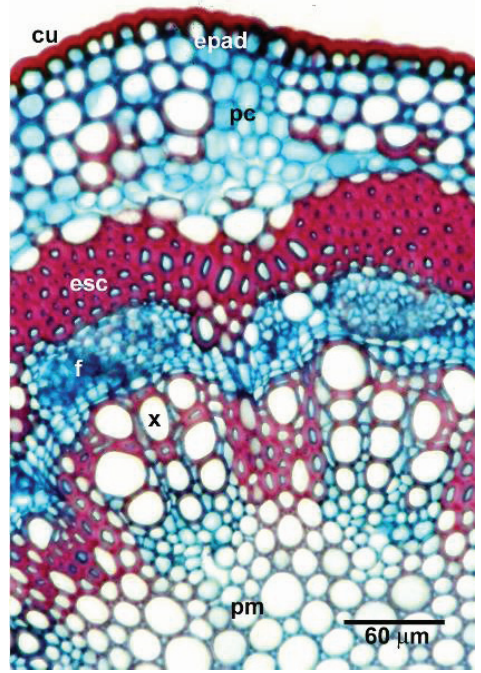

Figura 4. Raque e ráquila da folha de Memora nodosa (Silva Manso) Miers, Bignoniaceae, em secção transversal. A. Aspecto geral da raque. B. Aspecto geral da ráquila (raque secundária). C. Detalhe da organização estrutural da ráquila. cu: cutícula; epab: face abaxial da epiderme; epad: face adaxial da epiderme, esc: esclerênquima; f: floema; pc: parênquima cortical; pm: parênquima medular; x: xilema.
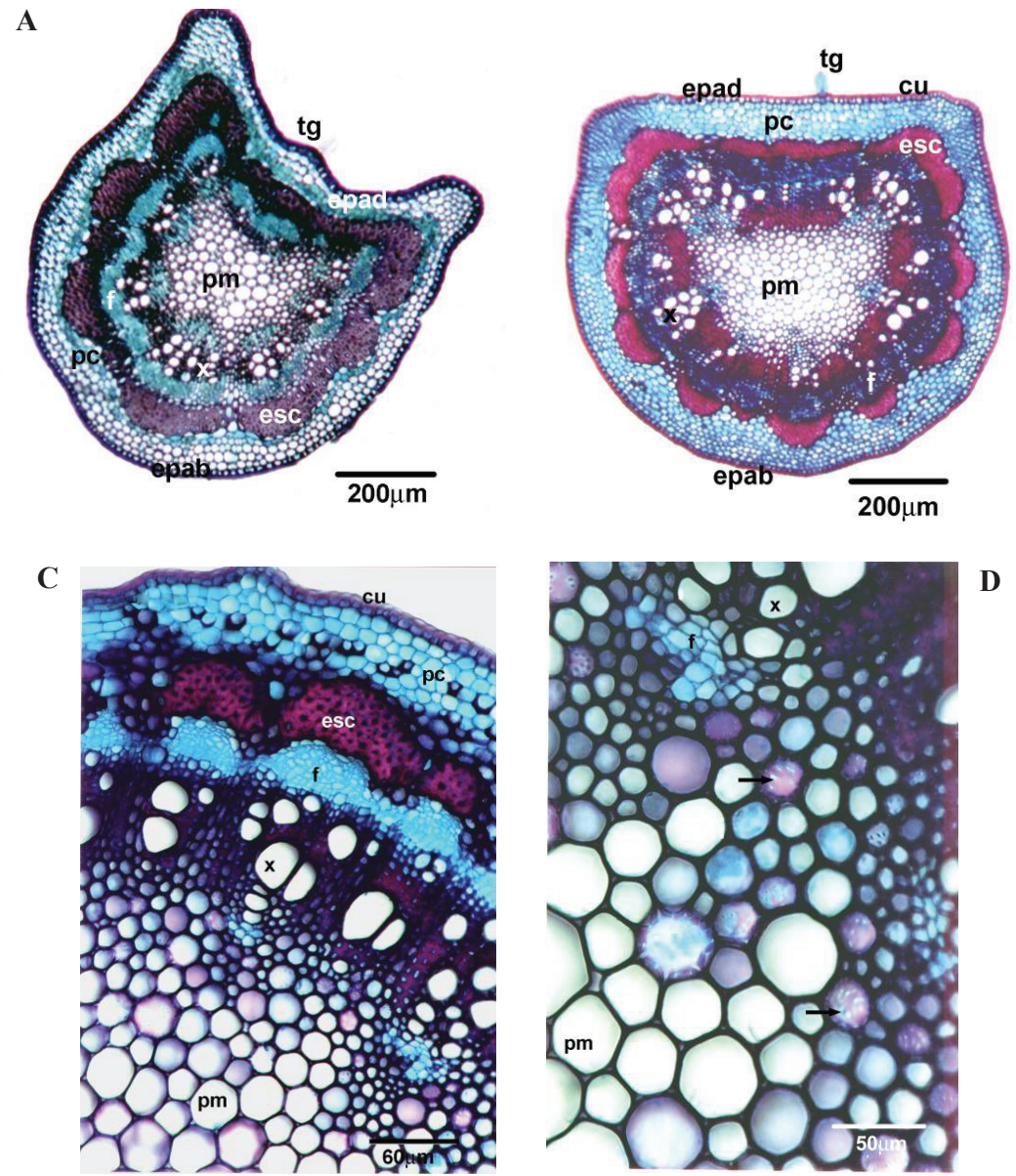

Figura 5. Peciólulo e pecíolo da folha de Memora nodosa (Silva Manso) Miers, Bignoniaceae, em secção transversal. A. Aspecto geral do peciólulo. B. Aspecto geral do pecíolo. C. Detalhe da organização estrutural do pecíolo. D. Detalhe do xilema e do parênquima medular do pecíolo, evidenciando pontoações (setas). cu: cutícula; ep: epiderme; epad: face adaxial da epiderme; epab: face abaxial da epiderme; esc: esclerênquima; f: floema; pc: parênquima cortical; pm: parênquima medular; tg: pelo glandular; x: xilema. 

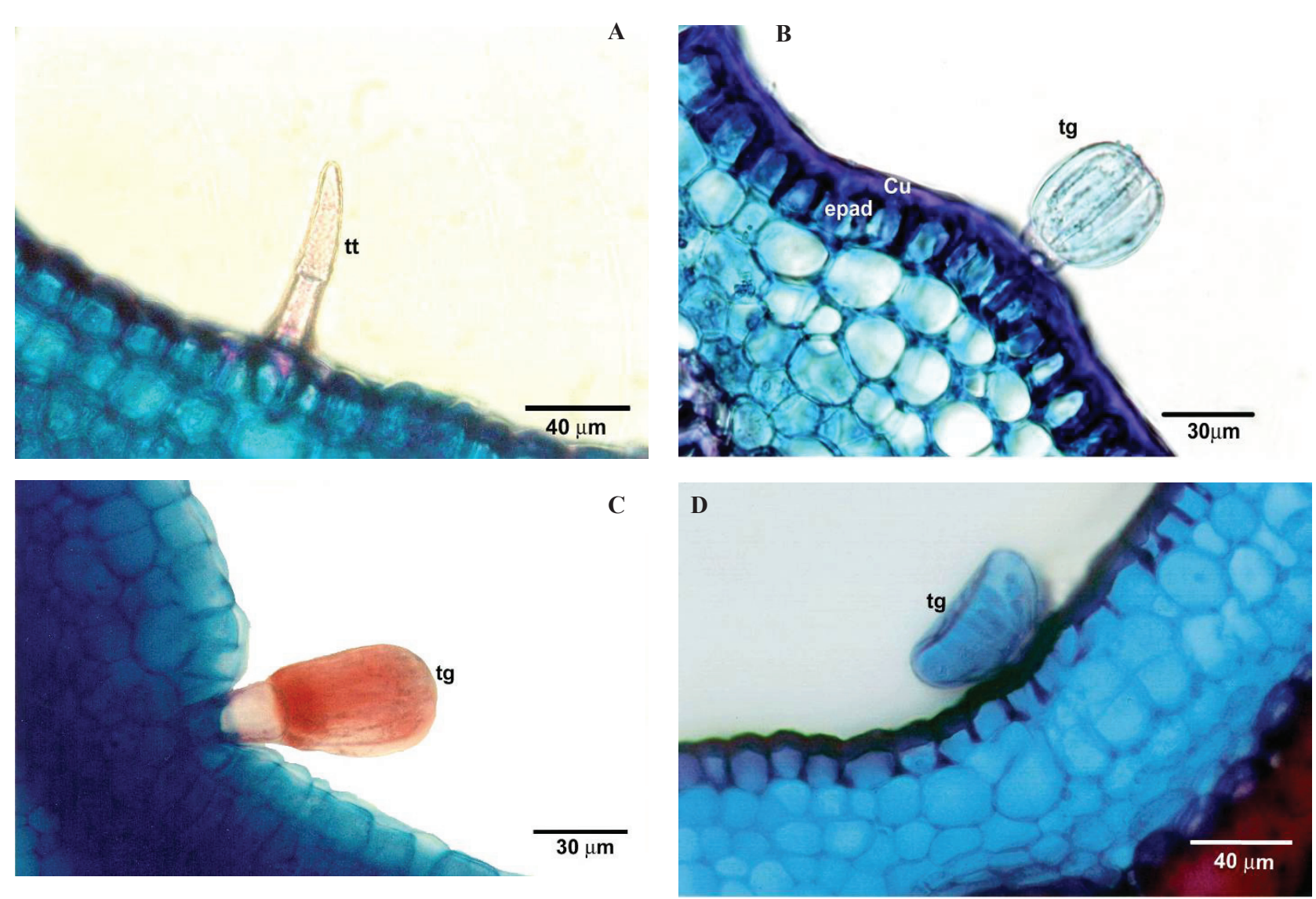

Figura 6. Secções das folhas de Memora nodosa (Silva Manso) Miers, Bignoniaceae. A. Detalhe da epiderme da ráquila com pêlo tector simples, pluricelular. B. Detalhe da face adaxial da epiderme do peciólulo com cutícula espessa e pêlo glandular com cabeça globosa. C. Detalhe do pêlo glandular com cabeça alongada na lâmina do foliólulo. D. Detalhe da face adaxial da epiderme da raque evidenciando cutícula espessa com flange e do pêlo glandular peltado. cu: cutícula; epad: face adaxial da epiderme, tt: pêlo tector; tg: pêlo glandular.

\section{DISCUSSÃO}

Memora nodosa é uma planta do Cerrado que se propaga vigorosamente em áreas onde a vegetação nativa foi retirada, podendo tornar-se indesejada. Em Goiás é comum encontrá-la em áreas destinadas à agropecuária e de Cerrado degradado por ocupação antrópica. Propriedades daninhas associadas com as Bignoniaceae são comuns e foram relatadas para Memora peregrina (Miers) Sandwith (Nunes, 1999), M. allamandiflora (Rodrigues et al., 2002) e para outras espécies dessa família (Duarte \& Jungensen, 2007; Lorenzi, 2008; Souza et al., 2007).

Morfologicamente, contribuem para a identificação de $M$. nodosa, a estrutura do caule, ereto ou trepador quando jovem e curvado e muito ramificado no terço superior quando adulto formando touceiras; o tamanho das folhas que contrasta com a relativamente pequena área foliar dos foliólulos, bem como, o conjunto de características das folhas e das flores. A variabilidade foliar verificada para $M$. nodosa foi relatada por Vidal (1978) como característica do gênero Memora e por
Seibert (1948) como sendo frequente nas trepadeiras da família Bignoniaceae.

As flores de $M$. nodosa são grandes e vistosas e apresentam as características gerais da família. Nessa pesquisa observou-se no terço superior do cálice, principalmente sobre as nervuras, grande quantidade de glândulas secretoras. Na corola foram observados muitos tricomas glandulares com pedicelos longos, na base dos estames. De acordo com Seibert (1948) a presença de glândulas no cálice e na corola é uma característica do gênero Memora.

Os dados morfológicos encontrados no presente trabalho estão de acordo com os descritos para essa espécie por Bureau \& Schumann (1897) e com os relatados para o gênero Memora por Vidal (1978), Gentry (1974, 1977, 1978) e Barroso et al. (1999).

A anatomia da epiderme do foliólulo de $M$. nodosa observada neste trabalho é similar à relatada por Vidal (1978) para espécies do gênero Memora e às observadas por Rodrigues et al. (2002) para $M$. allamandiflora. Cutícula espessa recobrindo a epiderme, principalmente na face adaxial é característica comum 
em Bignoniaceae e foram relatadas para Arrabidaea chica (Humb. \& Bonpl.) B. Verl. (Puhl et al., 2007), Jacaranda decurrens Cham. (Zatta et al., 2009), Jacaranda caroba (Vell.) A. DC. (Oliveira et al., 1996), porém nessas espécies, a cutícula está ornamentada por estrias, enquanto em $M$. nodosa a cutícula é lisa. Segundo Vannuci \& Rezende (2003), cutículas espessas são comuns em plantas que vivem em ambientes secos, pois a impregnação de cutina minimiza a perda de água.

O mesofilo de $M$. nodosa é dorsiventral, semelhante ao de M. allamandiflora (Rodrigues et al., 2002) e encontrado em outras espécies da família (Duarte \& Jungersen, 2007; Mauro et al., 2007; Puhl et al., 2007; Souza et al., 2007, Zatta et al., 2009). Destaca-se como característica de $M$. nodosa o parênquima paliçádico pluriestratificado, ocupando dois terços do mesofilo. Para M. allamandiflora, Jacaranda decurrens Cham., Jacaranda caroba (Vell). A. DC., Pyrostegia venusta (Ker Gawl) Miers., Arrabidaea chica (Humb. \& Bonpl.) B. Verl., Arrabidaea mutabilis Bureau \& K. Schum. e Anemopegma arvense (Vell.) Stellfeld., espécies de Bignoniaceae, o parênquima paliçádico está constituído por uma ou duas camadas de células que ocupam cerca de um terço do mesofilo (Duarte \& Jungensen, 2007; Hyakutake \& Grotta, 1965; Puhl et al., 2007; Rodrigues et al., 2002; Souza et al., 2007; Zatta et al., 2009). As folhas de $M$. nodosa são hipoestomáticas com estômatos predominantemente paracíticos, embora também sejam observados estômatos anisocíticos e ciclocíticos. Esses tipos de estômatos foram descritos por Metcalfe \& Chalk (1979) para espécies da família. Entre as Bignoniaceae estudadas anatomicamente observou-se que $P$. venusta (Duarte \& Jungersen, 2007) e $J$. decurrens (Zatta et al., 2009) possuem estômatos anomocíticos, A. chica (Puhl et al., 2007) estômatos anisocíticos, M. allamandiflora (Rodrigues et al., 2002) estômatos paracíticos e $A$. mutabilis (Souza et al., 2007) estômatos anomocíticos e paracíticos. Segundo Senna et al. (2007), a variedade estomática, como a observada em M. nodosa, pode estar associada a adaptações dos vegetais em locais com restrição de água.

Folhas pequenas e compactadas acompanhadas de mudanças na estrutura interna da folha, tais como cutícula bem desenvolvida, maior densidade do sistema vascular, parênquima paliçádico em maior quantidade que o esponjoso, como observado em $M$. nodosa, evidenciam caracteres xerofíticos (Appezzato-da-Glória \& CarmelloGuerreiro, 2003).

A raque, a ráquila, o pecíolo e o peciólulo de M. nodosa apresentam características anatômicas muito semelhantes, como epiderme uniestratifícada revestida por cutícula espessa, sistema vascular envolvido por bainha esclerenquimáticas e parênquima medular com células de tamanhos variados. Essas características também foram descritas por Rodrigues et al. (2002) para
M. allamandiflora. Sistema vascular revestido por tecido esclerificado foi relatado para as folhas de várias espécies de Bignoniaceae (Duarte \& Jungersen, 2007; Puhl et al., 2007; Rodrigues et al., 2002; Souza et al, 2007; Zatta et al., 2009).

Em M. nodosa os tricomas, tanto glandulares quanto tectores, foram observados com maior frequência na face adaxial das folhas jovens. O maior número de tricomas glandulares provavelmente está relacionado com mecanismo de proteção contra predadores, pois nessa fase de desenvolvimento as folhas são muito brilhantes e atrativas. Segundo Vidal (1978), tricomas tectores e glandulares (discoides, elipsoides ou capitadopeltado), variando de poucos a numerosos, esparsos na lâmina foliar ou em séries sobre as nervuras, ocorrem em ambas as faces dos foliólulos das espécies do gênero Memora. Estrutura semelhante a uma roseta foi descrita por Vidal (1978) na epiderme de espécies de gênero Memora como sendo estômatos circundados por células epiteliais, confirmado no presente estudo. Verificou-se a presença de cicatriz de pêlo semelhante à descrita por Rodrigues et al. (2002) para M. allamandiflora.

Os dados morfoanatômicos relatados no presente estudo constituem uma importante contribuição para a identificação botânica de Memora nodosa.

\section{REFERÊNCIAS}

Appezzato-da-Gloria B, Carmello-Guerreiro SM 2003. Anatomia Vegetal. Viçosa: Universidade Federal de Viçosa.

Barroso GM, Morim, MP, Peixoto AL, Ichaso CLF 1999. Frutos e sementes: morfologia aplicada à sistemática de dicotiledôneas. Viçosa: Universidade Federal de Viçosa.

Bozzola JJ, Russel LD 1992. Electron microscopy: principles and techniques for biologists. Boston: Jones and Bartlett Publishers.

Burreau E, Schumann C 1897. Bignoniaceae. In: Martius CFP (org.). Flora Brasiliensis, v.VIII, part. II, fasc. 121. Disponível em <http://florabrasiliensis.org.br/fviewer $>$. Acesso jun 2006.

Costa AF 2001. Farmacognosia experimental. 3 ed. Lisboa: Fundação Calouste Gulbenkian.

Duarte MR, Jungensen I 2007. Diagnose morfoanatômica de folha e caule de Pyrostegia venusta (Ker Gawl.) Miers, Bignoniaceae. Lat Am J Pharm 26: 70-75.

Gentry AH 1974. Studies in Bignoniaceae 12: new or noteworthy species of South American Bignoniaceae. Ann Mo Bot Gard 61: 872-885.

Gentry AH 1977. Studies in Bignoniaceae 25: new species and combinations in South American Bignoniaceae. Ann Mo Bot Gard 64: 311-319.

Gentry AH 1978. Studies in Bignoniaceae 31: new species and combinations from Amazonian Peru and Brazil. Ann Mo Bot Gard 65: 725-735. 
Gentry AH 1992. A synopsis of Bignoniaceae ethnobotany and economic botany. Ann Mo Bot Gard 79: 53-64.

Ghouse AK, Yunus M 1972. Preparation of epidermal peels from leaves of Gymnosperm by treatment with hot, $60^{\circ}$

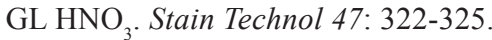

Gonçalves EG, Lorenzi H 2007. Morfologia vegetal: organografia e dicionário ilustrado de morfologia das plantas vasculares. São Paulo: Instituto Plantarum de Estudos da Flora.

Hyakutake S, Grotta AS 1965. Contribuição ao estudo morfológico e anatômico de Anemopaegma arvense (Vell.) Stellfeld. var. petiolata Bur. Bignoniaceae. Rev Fac Farm Bioquim. 3(1):51-78.

Judd WS, Campbell CS, Kellog EA, Stevens PF 1999. Plant systematics: a phylogenetic approach. Sunderland: Sinauer Associates, Inc.Publishers.

Kraus J, Arduin M 1997. Manual básico de métodos em morfologia vegetal. Seropédica: EDUR.

Lorenzi H 2008. Plantas daninhas do Brasil: terrestres, parasitas e tóxicas. 4. ed. Nova Odessa: Instituto Plantarum.

Luque R, Sousa HC, Kraus JE 1996. Métodos de coloração de Roeser (1972) modificado e Kropp (1972) visando a substituição do azul de astra pelo azul de alcião 6GS ou 8GX. Acta Bot Brasil 10: 199-212.

Mauro C, Pereira AMS, Silva CP, Missima J, Ohnuk T, Rinaldi RB 2007. Anatomical study of species from savannalike formation, Anemopaegma arvense (Vell.) Stellf. ex de Souza (catuaba), Zeyheria montana Mart. (bolsa-depastor) and Jacaranda decurrens Chamisso (caroba) Bignoniaceae. Rev Bras Farmacog 17: 262-265.

Metcalfe CR, Chalk L 1979. Anatomy of the dicotyledons. Systematic anatomy of the leaf and stem. V. I Oxford: Clarendon Press.

Missouri Botanical Garden 2008. <http://www.tropicos.org>. Acesso jan 2008.

Nunes SG 1999. Memora peregrina (Miers) Sandw. nova planta invasora de pastagem. Embrapa. http:/www.cnpgc. embrapa.br/ rosana/ciganinha/folder/30caracteristicas. htlm. Acesso nov 2005.

Oliveira F, Akisue G, Akisue MK 1996. Farmacognosia. São Paulo: Atheneu.

Puhl MCMN, Milaneze-Gutierre MA, Nakamura CV, Cortez DAG 2007. Morfoanatomia das folhas e dos caules jovens de Arrabidaea chica (Humb. \& Bonpl.) B. Verl. (Bignoniaceae). Lat Am J Pharm 26: 224-229.

Rodrigues ST, Potiguara RCV, Nascimento ME, Gomes JI 2002. Características morfo-anatômicas de plantas invasoras. I-Memora allamandiflora Bur. Es K. Schum. (Bignoniaceae). Bol Mus Paraense Emílio Goeldi Ser 18: 331-347.

Seibert RJ 1948. The use of glands in a taxonomic consideration of the family Bignoniaceae. Ann Mo Bot Gard 35: 123 137.

Senna JOA, Zaidan HA, Castro PRC 2007. Transpiration and stomatal resistance variations of perennial tropical crops Ander soil water availability conditions and water deficit. Braz Arch Biol Technol 50: 225-230.

Silva SR 1998. Plantas do cerrado utilizadas pelas comunidades de região do Grande Sertão Veredas. Brasília: Funatura.

Siqueira JC 1988. Plantas medicinais: identificação e uso das espécies do cerrado. São Paulo: Loyola.

Soares SF 2008. Estudos da repelência de extratos de plantas e do DEET ( $N, N$-diethyl-M-toluamide) em Amblyomma cajannense (Acari:Ixodidae). Dissertação de Mestrado. Programa de Pós-graduação em Ciência Animal, Faculdade de Veterinária, Universidade Federal de Goiás.

Souza LA, Lopes WQLL, Almeida OJG 2007. Morfoanatomia da plântula e do tirodendro de Arrabidaea mutabilis Bureau \& K. Schum. (Bignoniaceae). Acta Sci Biol Sci 29: 131-136.

Tresvenzol LMF, Queiroz DC, Rezende RC, Nascimento TL, Rosa VS, Paula JL 2005. Estudo farmacognóstico de Memora nodosa (Manso) Miers. Rev Eletron Farm 2: 221-223.

Tresvenzol L M F, Fiuza TS, Pimenta FC, Zatta DT, Bara MTF, Ferri PH, Lima ABM, Paula JR 2009. Composição química do óleo essencial e atividade antimicrobiana da Memora nodosa (Bignoniaceae). Lat Am J Pharm 28: 53-59.

Vannuci AL, Rezende MH 2003. Anatomia vegetal: noções básicas. Goiânia: Universidade Federal de Goiás.

Vidal MRR 1978. As folhas bipenadas - suas características e ocorrências em algumas dicotiledôneas. Rodriguesia 30: $169-358$

Vidal WN, Vidal MRR 2000. Botânica - Organografia: quadros sinóticos ilustrados de fanerógamos. Viçosa: UFV.

Zatta DT, Oliveira FNM, Bara MTF, Rezende MH, Barbosa LCS, Garrote CFD, Tresvenzol LMF, Fiuza TS, Paula JR 2009. Morfoanatomia foliar e parâmetros de qualidade da Jacaranda decurrens (Bignoniaceae). Lat Am J Pharm 28: 358-365. 